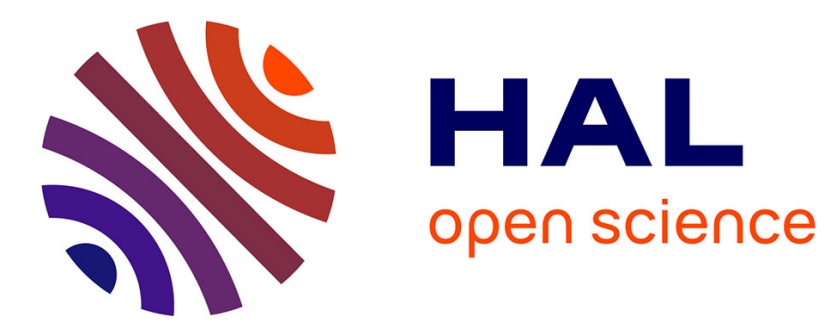

\title{
Silicon Clathrate Films for Photovoltaic Applications
}

Thomas Fix, Romain Vollondat, Arechkik Ameur, Stephane Roques, Jean-Luc

Rehspringer, Céline Chevalier, Dominique Muller, Abdelilah Slaoui

\section{To cite this version:}

Thomas Fix, Romain Vollondat, Arechkik Ameur, Stephane Roques, Jean-Luc Rehspringer, et al.. Silicon Clathrate Films for Photovoltaic Applications. Journal of Physical Chemistry C, 2020, 124 (28), pp.14972-14977. 10.1021/acs.jpcc.0c02712 . hal-02914281

\section{HAL Id: hal-02914281 \\ https://hal.science/hal-02914281}

Submitted on 5 Nov 2020

HAL is a multi-disciplinary open access archive for the deposit and dissemination of scientific research documents, whether they are published or not. The documents may come from teaching and research institutions in France or abroad, or from public or private research centers.
L'archive ouverte pluridisciplinaire HAL, est destinée au dépôt et à la diffusion de documents scientifiques de niveau recherche, publiés ou non, émanant des établissements d'enseignement et de recherche français ou étrangers, des laboratoires publics ou privés. 


\section{Silicon Clathrate Films for Photovoltaic Applications}

Thomas Fix $^{1 *}$, Romain Vollondat ${ }^{1}$, Arechkik Ameur ${ }^{1,2}$, Stéphane Roques ${ }^{1}$, Jean-Luc Rehspringer ${ }^{3}$, Céline Chevalier ${ }^{4}$, Dominique Muller ${ }^{1}$, Abdelilah Slaoui $^{1}$

${ }^{1}$ ICube laboratory (Université de Strasbourg and CNRS), 23 rue du Loess, BP 20 CR, F-67037 Strasbourg Cedex 2, France

${ }^{2}$ School of Science and Engineering, Al Akhawayn University, Ifrane, Morocco

${ }^{3}$ Institut de Physique et Chimie des Matériaux de Strasbourg (IPCMS), UMR 7504 CNRS and Université de Strasbourg, 23 rue du Loess, BP 43, F-67034 Strasbourg Cedex 2, France

${ }^{4}$ Université de Lyon ; Institut des Nanotechnologies de Lyon INL-UMR5270, CNRS ; INSA Lyon ; Villeurbanne, F-69621, France

* Corresponding author. Tel.: +33 388106334, Fax +33 388106548. E-mail address: tfix@unistra.fr 


\section{Abstract}

Silicon clathrates are allotropes of silicon that show great promises for optoelectronics and batteries. However silicon clathrates in the form of films are relatively new and devices based on this material still have to be engineered. In this work we present a protocol for silicon clathrates film fabrication that does not necessitate a glove box. We show that dense films can be obtained with a pressure annealing treatment and that the films can be measured by atomic force microscopy. Ion implantation of $\mathrm{P}, \mathrm{B}$ and As is performed on the clathrate films. Early photovoltaic devices are presented, with a maximum short circuit current density of $0.11 \mathrm{~mA} / \mathrm{cm}^{2}$. 


\section{Introduction}

Diamond silicon is the second most abundant element on earth. Silicon (Si) is the most used element in semiconductor technology. The main forms of $\mathrm{Si}$ encountered in research and industry are monocrystalline, multi-crystalline and amorphous Si. An allotrope of Si called Si clathrate was discovered in $1965^{1}$. It is composed of a framework of hollow spheres of various sizes, similar to carbon fullerenes further discovered in 1985 , with the ability to host guest atoms. Although practical applications of Si clathrates were not developed, this topic has regained interest with the possibility to fabricate Si clathrates in the form of films ${ }^{2-4}$. There are two main types of applications for these materials: optoelectronics ${ }^{5}$ and batteries ${ }^{6}$. In the first case, the $\mathrm{Na}_{x} \mathrm{Si}_{136}$ type II binary clathrate structure presents semiconducting properties and is able to reach a $1.9 \mathrm{eV}$ quasi-direct bandgap ${ }^{7}$. Furthermore the material presents the advantage of a direct bandgap as opposed to conventional diamond silicon ${ }^{8}$. In the second case, the large size of spheres composing the Si clathrates enables a high storage capacity within the cage that can be used for lithium or sodium ion batteries ${ }^{9-12}$. Thermoelectric properties of clathrates also seem favourable ${ }^{13,14}$. Coming back to optoelectronics, Si clathrate films (SCF) have been proposed to be used in solar cells ${ }^{5,8,15-19}$. Their main advantage compared to diamond $\mathrm{Si}$ is that diamond $\mathrm{Si}$ has an indirect bandgap of $1.1 \mathrm{eV}$ and a direct bandgap of $3.4 \mathrm{eV}$ which makes it a poor solar spectrum absorber. Thus the diamond Si absorber has to be thick $(100 \mu \mathrm{m})$ and at the same time very pure to provide a large minority carrier diffusion length ${ }^{15}$. Many efforts have been undertaken to improve the optical properties of diamond $\mathrm{Si}$, such as superlattices ${ }^{20}$, nanopatterning ${ }^{21}$, and plasmonics ${ }^{22,23}$.

Recently, an attempt was made to fabricate solar cells based on $\mathrm{Na}_{\times} \mathrm{Si}_{136}{ }^{8}$. The short-circuit current, open-circuit voltage and conversion efficiency were low, $9.2 \mathrm{nA}, 0.036 \mathrm{~V}$ and $10^{-5} \%$ respectively. In this work, we describe our fabrication process to obtain type I and type II SCF and we describe a substantial improvement of the photovoltaic (PV) properties using ion implantation. 


\section{Methods}

The method to fabricate SCF is similar to the ones reported in the literature, involving two annealing processes. The first annealing is performed as follows: a Na slice of mass around $1.2 \mathrm{~g}$ is cut from sodium sticks (purity 99\%, Alfa Aesar) and placed into cyclohexane (99+\%) to prevent oxidation. The Na material and related compounds should be handled with safety precautions. The Na slice is then put at the bottom of an Inconel crucible. A c-Si (001) substrate of thickness $0.5 \mathrm{~mm}$ and size $54 \times 37 \mathrm{~mm}^{2}$ is cleaned with $\mathrm{HF}$ ( $\mathrm{HF}: \mathrm{H}_{2} \mathrm{O}(1: 10)$ for $2 \mathrm{~min}$ ), rinsed with deionised water, placed on top of the crucible. The c-Si substrate is p-type with a resistivity of $1-5 \Omega \cdot \mathrm{cm}$. The substrate is covering totally the crucible and is about $1 \mathrm{~cm}$ above the Na slice. The crucible and sample are then inserted into a stainless-steel tube (diameter $44.5 \mathrm{~mm}$, length $1 \mathrm{~m}$, Inox SST304) which is itself placed into a tubular furnace. Some Ta in the form of wire is also inserted in the tube with the aim to absorb any residual oxygen in the tube. The stainless-steel tube is flushed with $\operatorname{Ar}(99.99990 \%)$ for $15 \mathrm{~min}$, a pressure of $\operatorname{Ar}$ of $1.6 \cdot 10^{5} \mathrm{~Pa}$ is applied by closing the tube with valves on each side. The tube is then heated with a ramp of $5^{\circ} \mathrm{C} / \mathrm{min}$ to a temperature of $480-650^{\circ} \mathrm{C}$ and maintained at this temperature for $19 \mathrm{~h}$. The tube is then naturally cooled down to room temperature. The tube is flushed with $\mathrm{Ar}$ and the substrate is taken out. The sample is then quickly transferred to a quartz tube which is pumped down to a dynamic pressure of $10^{-5} \mathrm{~Pa}$. A furnace is placed around the quartz tube which is heated to $400^{\circ} \mathrm{C}$ for $3 \mathrm{~h}$ under dynamic vacuum conditions and naturally cooled down to room temperature. Finally, the samples are washed with deionised water to remove remaining $\mathrm{Na}$ on the surface.

In order to improve the quality of the films, some SCF samples were press annealed in air at a temperature of $200^{\circ} \mathrm{C}$ and $250^{\circ} \mathrm{C}$ for 30 min with a force of $2 \mathrm{kN}$. The thermal treatment under pressure system is a hydraulic system (Rondol) with two steel plates with integrated and regulated heating up to 
$300^{\circ} \mathrm{C}$. The applied force of $2 \mathrm{kN}$ is the one applied by the system to the entire plates $\left(15 \times 15 \mathrm{~cm}^{2}\right)$ which corresponds to a pressure of $10^{6} \mathrm{~Pa}$ for the size of sample (about $20 \mathrm{~cm}^{2}$ ).

X-ray diffraction (XRD) was performed with a Bruker D8 diffractometer in Bragg-Brentano configuration with a $\mathrm{Cu} \mathrm{K} \mathrm{K}_{\alpha}$ wavelength of $0.15418 \mathrm{~nm}$. Scanning electron microscopy (SEM) was performed with a JEOL $6700 \mathrm{~F}$ equipped with a field-emission gun (FEG), operating at $3 \mathrm{kV}$ in the SEI mode instrument.

The surface of SCF was investigated using atomic force microscopy (AFM) with a NT-MDT Smena B AFM in tapping mode.

Concerning optical measurements, Raman spectroscopy was performed at room temperature with a JOBIN YVON LabRam ARamis with a $532 \mathrm{~nm}$ excitation. Spectroscopic ellipsometry was performed with an HORIBA Uvisel Lt M200 FGMS (210-880 nm). Photoluminescence (PL) was carried out between 24K and room temperature using an excitation at $355 \mathrm{~nm}$ with a frequency-tripled neodymium-doped yttrium aluminum garnet (Nd-YAG) laser. The laser pulse duration, frequency and power were $10 \mathrm{~ns}, 20$ $\mathrm{kHz}$ and up to $100 \mathrm{~mW}\left(15.6 \mathrm{~W} \cdot \mathrm{cm}^{-2}\right)$, respectively. The PL signal was collected by means of a concave mirror into an optical fiber and analyzed by a multichannel CCD. The PL signal was integrated over time for a duration of $800 \mathrm{~ms}$.

The ion implantation of B, P and As in the as-grown SCF was performed at ICube with an EATON 200 MC. The dose was $5 \times 10^{15} \mathrm{at} / \mathrm{cm}^{2}$ and the energy was $30 \mathrm{keV}$. The samples were then annealed in a rapid thermal annealing (RTA) system at $950^{\circ} \mathrm{C}$ for $30 \mathrm{~s}$ for the activation of dopants. More specifically the samples were RTA annealed under Ar atmosphere ( $30 \mathrm{~s}$ purge), heated from about $20^{\circ} \mathrm{C}$ to $950^{\circ} \mathrm{C}$ in $6 \mathrm{~s}$, kept at $950^{\circ} \mathrm{C}$ for $30 \mathrm{~s}$ and cooled down with water cooling $\left(950^{\circ} \mathrm{C}\right.$ to $500^{\circ} \mathrm{C}$ reached in $12 \mathrm{~s}$, total cooling time from $950^{\circ} \mathrm{C}$ to $35^{\circ} \mathrm{C}$ in $\left.180 \mathrm{~s}\right)$. 
I-V characteristics were performed at room temperature using an Oriel Solar Simulator in AM1.5G conditions and a Keithley 2461 SourceMeter. Unless stated otherwise, the contacts were made of thick Ag paste in a corner of the sample for the top contact and over the whole back surface for the bottom contact.

\section{Results and Discussion}

Figures 1a) and b) show the experimental procedure to obtain SCF on c-Si (001) as described in the experimental section. Before having switched to this procedure involving bulk $\mathrm{Na}$ as a precursor, two alternative methods were tested. The first one involved deposition of $\mathrm{NaF}$ on $\mathrm{c}-\mathrm{Si}$ and subsequent annealing, and the second ion $\mathrm{Na}$ implantation in $\mathrm{c}-\mathrm{Si}$. For both methods the amount of Na incorporated in Si was insufficient to form SCF. Therefore in this work only the fabrication of SCF with Na source is described. It should be noted that in contrast to previous work ${ }^{3,4,8}$, no glove box is necessary in the protocol and that the design of the experiment is quite simple which should enable more scientists to elaborate SCF in the future. Using this method, a large area of SCF of size about $4.5 \mathrm{~cm} \times 1.5 \mathrm{~cm}$ can be produced as shown in Figure 1c). It should be noted that initial experiments were producing SCF that were exfoliating from the substrate. This issue was solved by naturally cooling down the sample after the second annealing and maintaining the furnace around the quartz tube so that the cooling down is slow and takes about $10 \mathrm{~h}$ to reach room temperature. 
Figure 1: a), b) sketches of the setup for the first and second annealing respectively; c) picture showing SCF on c-Si (001)

a)

To Ar cylinder

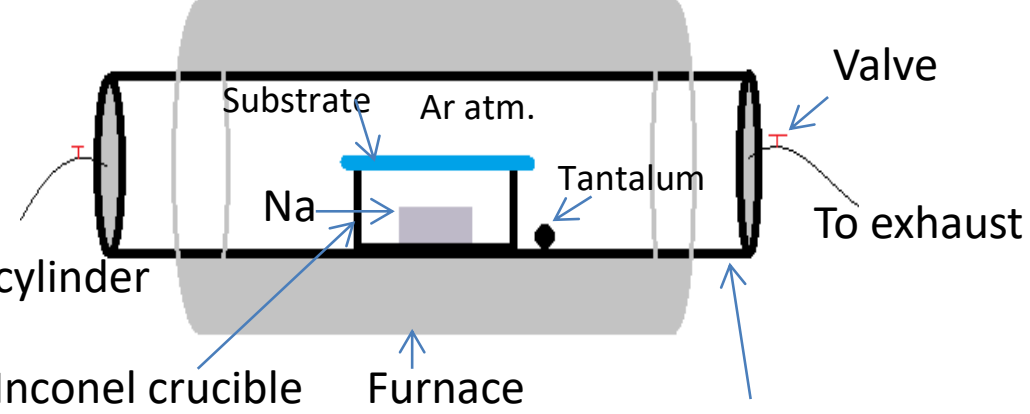

Sealed stainless-steel tube

b)

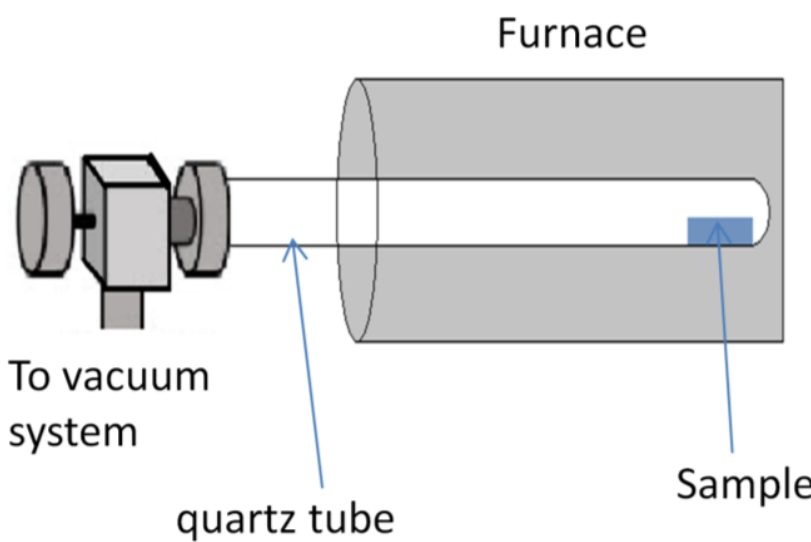

c)

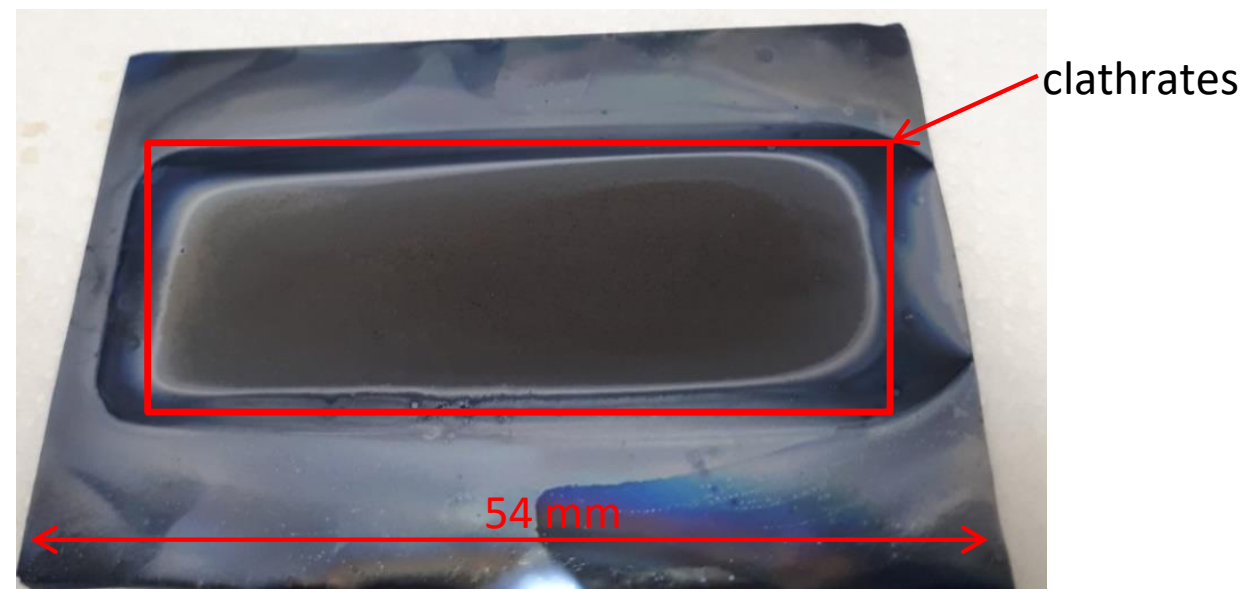


To ensure that SCF were produced, XRD was used. Figure 2a) shows the XRD spectrum of a SCF sample on c-Si (001) with the first annealing at a temperature of $550^{\circ} \mathrm{C}$. It shows a mixture of type I $\left(\mathrm{Na}_{8} \mathrm{Si}_{46}\right)$ and type II $\left(\mathrm{Na}_{x \leq 24} \mathrm{Si}_{136}\right)$ clathrates. Type II clathrates are the most promising silicon clathrates due to their appealing optoelectronic properties. Previous work had shown that a first annealing temperature of $500^{\circ} \mathrm{C}$ was leading to type I clathrates while a temperature of $600^{\circ} \mathrm{C}$ gave type II clathrates ${ }^{3}$. Therefore, while keeping the second annealing conditions constant, we varied the temperature of the first annealing between $480^{\circ} \mathrm{C}$ and $650^{\circ} \mathrm{C}$ for $19 \mathrm{~h}$. The two extreme temperature values, $480^{\circ} \mathrm{C}$ and $650^{\circ} \mathrm{C}$ did not provide any silicon clathrates, while the intermediate temperatures between $500^{\circ} \mathrm{C}$ and $600^{\circ} \mathrm{C}$ all provided a mixture of type I and type II clathrates. In order to give an estimation of the clathrates of type I vs. type II predominance, we plotted in Figure $2 \mathrm{~b}$ ) the ratio between the two most intense reflections for type I (321) and type II (531). According to this graph, it is found that the first annealing temperature providing the highest ratio of type $I I$ is $550^{\circ} \mathrm{C}$. Other conditions were also varied with limited success, such as the first annealing duration (no SCF for $6 \mathrm{~h}$ duration, mostly type I for $12 \mathrm{~h}$, type I and II for $19 \mathrm{~h}$ ), and the Ar pressure inside the first furnace $\left(1.6 \cdot 10^{5}\right.$ to $2.6 \cdot 10^{5}$ Pa gave no further improvement). We also compared the XRD spectrum of Figure 2a) with reference 4 where the type I/type II weight ratio was precisely estimated and we find a type I/type II weight ratio of roughly $20 / 80$.

Further confirmation of the presence of silicon clathrates is given by Raman spectroscopy (see Supplementary Information (SI) Figure S2) where several peaks are identified for type II clathrates ${ }^{24}$ and two peaks for type I clathrates ${ }^{25}$.

Figure 2: a) XRD spectrum of SCF (first annealing at $550^{\circ} \mathrm{C}$ ) and the JCPDS reference for type I ( $\mathrm{Na}_{8} \mathrm{Si}_{46}$ ) and type II ( $\left.\mathrm{NaSi}_{136}\right)$ silicon clathrates b) ratio between the intensity of type I (321) and type II (531) reflections vs. the temperature of the first annealing. 


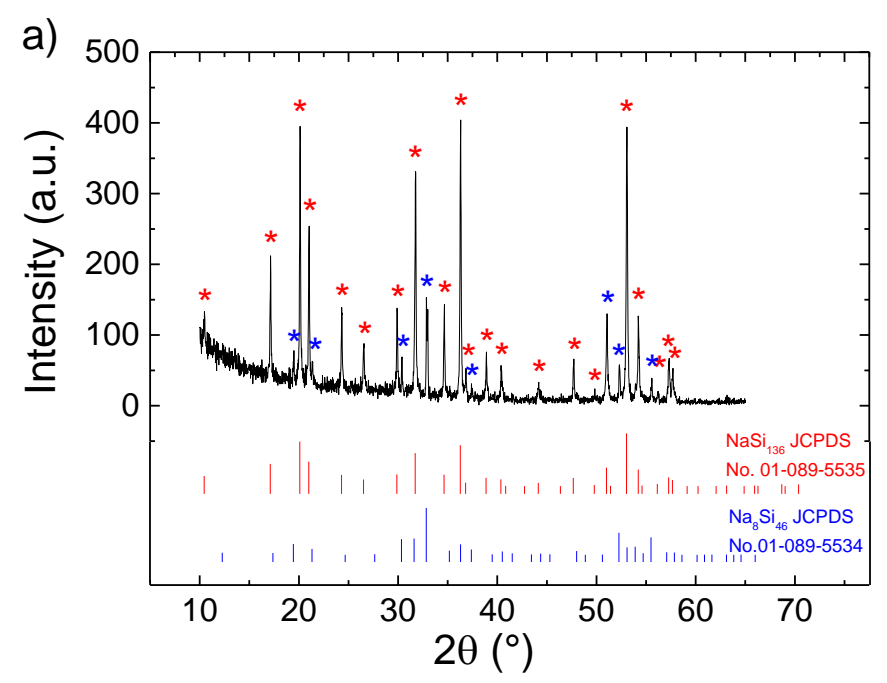

b)

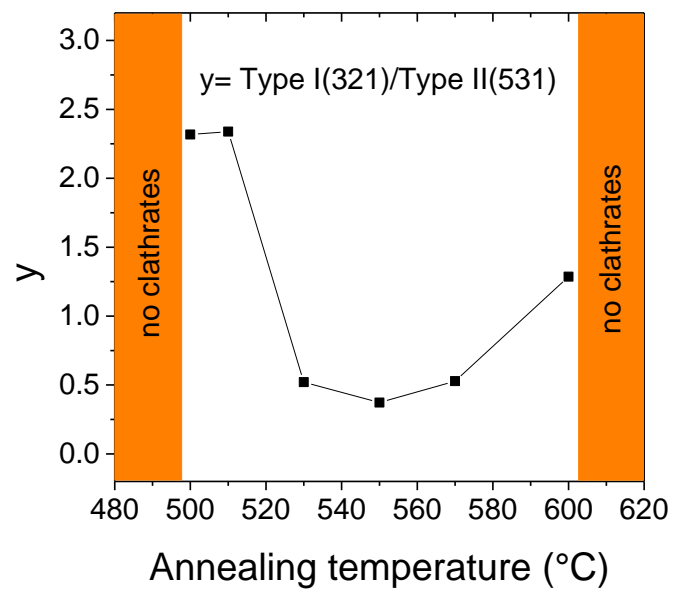

Figure 3a) shows the SEM image in cross-section of a SCF sample. It shows a very porous morphology, large variations in the surface (see SI Figure S1) and the presence of cracks on the surface originating from the decomposition of the Zintl phase. Such a surface and morphology is detrimental for the production of devices. Therefore we performed press annealing on SCF films. Figure 3b) shows a SEM cross-section of a SCF sample press annealed at $250^{\circ} \mathrm{C}$. The porous structure observed in the as-grown samples has disappeared and a compact film is observed. Thanks to the improvement of the surface properties, it was possible to perform AFM on such samples. Figure 4 shows the topography observed by AFM of the surface of SCF on c-Si after press annealing at $250^{\circ} \mathrm{C}$. This is the first time that SCF roughness is low enough to be able to be measured by AFM. Grains of size about $200 \mathrm{~nm}$ can be observed and the root-mean-square roughness (RMS) in a clean $5 \times 5 \mu \mathrm{m}^{2}$ and $1 \times 1 \mu \mathrm{m}^{2}$ area is about $100 \mathrm{~nm}$ and $10 \mathrm{~nm}$ respectively. While such values are still very high compared to film roughness prepared by physical methods such as pulsed laser deposition (PLD) or magnetron sputtering, it represents a first step into the integration of SCF into film technologies. As we will describe in the section on PV properties, contacts could be deposited on the SCF without creating short-circuits which means that the films are viable for 
further processing. The pressure annealing not only resulted in a morphology change, but also in a recrystallization of SCF as the annealing temperature was increased; the recrystallization led to more intense and less numerous XRD reflections (see SI Figure S3). The position of the peaks does not vary after pressure annealing but only their intensity, which indicates that the same phase is preserved but the grains are reorganised and recrystallised to allow a denser film. However, after press annealing at $250{ }^{\circ} \mathrm{C}$ no remaining type II silicon clathrate peaks are visible.

Figure 3: cross-sectional SEM image showing SCF on c-Si a) as fabricated b) after press annealing at $250^{\circ} \mathrm{C}$.

a)

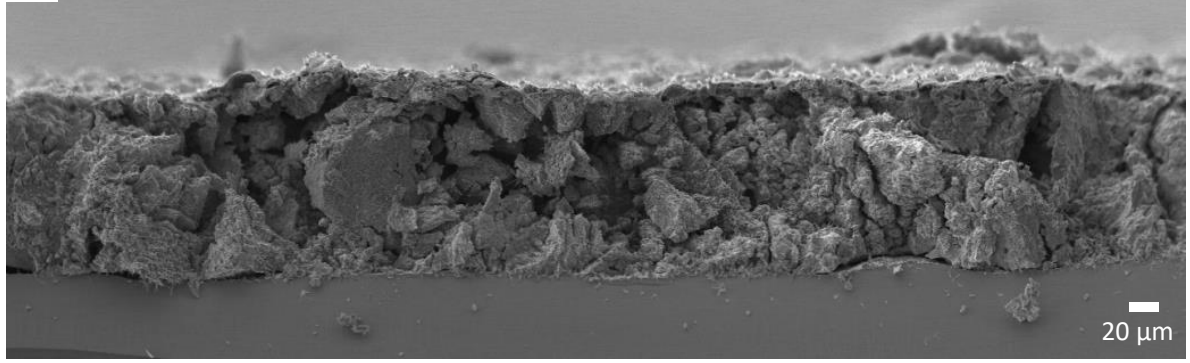

b)

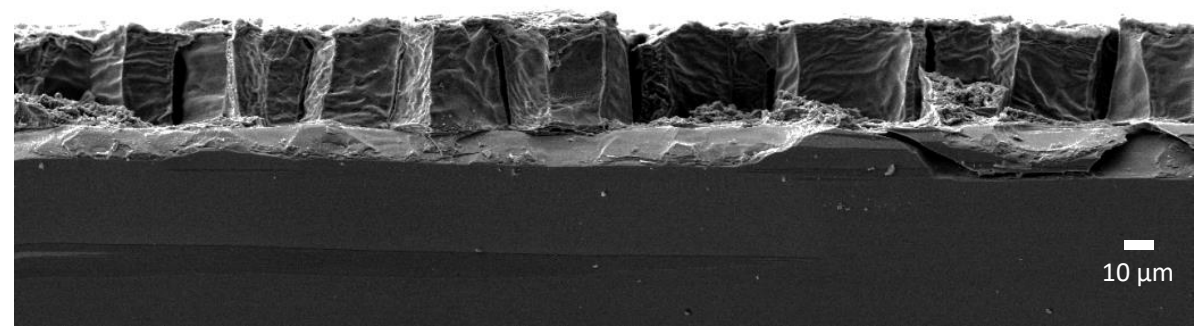


Figure 4: AFM topography images of a silicon clathrate film on c-Si after press annealing at $250^{\circ} \mathrm{C}$.
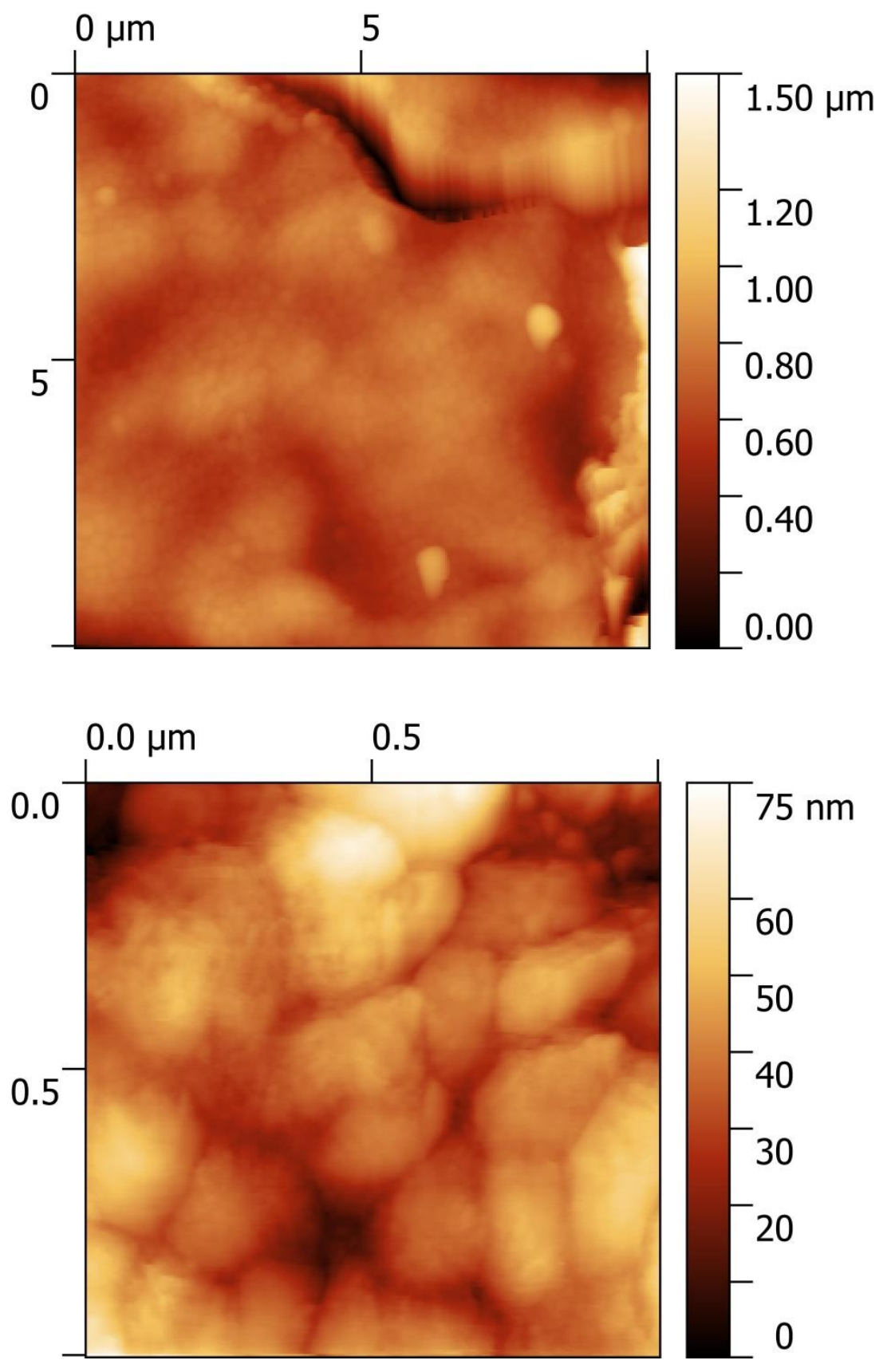

Concerning the composition, the as-grown SCF analysed by Energy Dispersive Spectroscopy (EDS) in the SEM provided a concentration of one atom of $\mathrm{Na}$ for 4.6 atoms of $\mathrm{Si}$ and one Na for 11 atoms of Si before 
and after washing the SCF with deionised water respectively. Further repetition of the second annealing in vacuum tends to reduce the amount of $\mathrm{Na}$. Some solutions using a cold plate ${ }^{4}$ or iodine treatment 8,26 have been proposed to effectively reduce the amount of $\mathrm{Na}$ to negligible levels and this will represent a further improvement of the current work.

We now consider the optical properties of the SCF. Spectroscopic ellipsometry was used to determine the refractive index, extinction and absorption coefficients (see SI Figure S4). At $600 \mathrm{~nm}$, the absorption coefficient is comparable to that of a-Si. It is about $2 \times 10^{4} \mathrm{~cm}^{-1}$ which is very close to previous experiments by photothermal deflection spectroscopy ${ }^{16}$. Noisy signal is obtained due to the low reflective nature of the SCF and rough surface. It is interesting to notice that the refractive index is about 1.5, much lower than for d-Si in the visible range. The Tauc-plot (SI Figure S4c) indicates a direct bandgap in the 1.7-1.9 eV range which is comparable to previous values ${ }^{7}$. The PL properties were also measured (SI Figure S5). A very wide PL peak of centre around $600 \mathrm{~nm}$ and full width at half maximum about 300 $\mathrm{nm}$ is observed, but no sign of the bandgap of SCF could be observed, even by lowering down the temperature to $24 \mathrm{~K}$. The fact that the intensity of the PL decreases at low temperature can be a sign that the PL observed is mainly due to defects. It was proposed in Ref. 18 that the broadness of the PL is due to defects occurring with Na sublimation during the annealing under dynamic vacuum.

Concerning the electrical properties, because our SCF is fabricated on p-Si, no Hall effect measurements are possible. However in Ref. ${ }^{8}$ it was reported that the SCF was of n-type nature. Thus, early PV devices were fabricated in the hope of having a $p-n$ junction ( $p$-Si substrate - n-SCF). In contrast to previous work in the present case a hot-point probe method indicates for SCF neither a clear n- or p-type behaviour, and therefore it is presented in the following as " $\mathrm{i}$ " for intrinsic. This discrepancy can be explained by several reasons such as the fact that here we have a mixture of type I and type II Si clathrates and that the $\mathrm{Na}$ content is still high compared to the literature. It should be noted that " $\mathrm{i}$ " is only used as a 
guideline and that the non-implanted SCF is conductive (10 $\Omega \cdot \mathrm{cm}$ resistivity) and thus not a real intrinsic material. Still it shares the property common to intrinsic semiconductors that neither a clear $n$-type or $p$ type behaviour is observed. This was also confirmed by Hall effect on SCF produced from real intrinsic Si wafers.

The size of the cell is about $0.5 \mathrm{~cm}^{2}$. Figure $5 \mathrm{a}$ ) shows the IV in dark and under 1 sun of SCF on $\mathrm{p}-\mathrm{Si}$ contacted with Ag. It shows a very small short circuit current density $\left(\mathrm{J}_{\mathrm{sc}}\right)$ of $9.2 \cdot 10^{-4} \mathrm{~mA} / \mathrm{cm}^{2}$ and a very small open circuit voltage $\left(\mathrm{V}_{\mathrm{OC}}\right)$ of $41 \mathrm{mV}$. It can be observed in the inset that the IV curve is slightly asymmetric but does not show a nice diode rectification behaviour. We expect here an i-n junction and therefore PV properties are poor. To improve this, the SCF films were doped at the surface by ion implantation, using a low energy to minimise amorphization by the ion beam. It should be noted that little is known about doping in silicon clathrates and therefore we performed pioneering work using $\mathrm{B}, \mathrm{P}$ and As as dopants. At $30 \mathrm{keV}$, we calculated with the SRIM software that the projected range $R_{p}$ of the implantation is very small compared to the thickness of the SCF $\left(R_{p}\right.$ of $132 \mathrm{~nm}$ for $B, 52 \mathrm{~nm}$ for $P, 32 \mathrm{~nm}$ for As, compared to SCF thicknesses higher than $50 \mu \mathrm{m}$ ). Rapid thermal annealing was performed after implantation with the aim to activate the dopants, while limiting exodiffusion. Therefore, doping affects only the top part of the SCF. It was checked by Raman that the implantation and RTA do not alter the clathrate phase (SI Figure S6). Figure 5b) shows the device implanted with B. B is traditionally a p-type dopant in diamond silicon. In this case, the PV properties have disappeared and the IV curve is quite symmetrical. This is not surprising if we consider that we have formed a $p-i-p$ structure. Next, implantation of $\mathrm{P}$ was performed (Figure $5 \mathrm{c}$ ). $\mathrm{P}$ is a $\mathrm{n}$-type dopant in diamond $\mathrm{Si}$. A small $\mathrm{J}_{\mathrm{SC}}$ and $\mathrm{V}_{\mathrm{OC}}$ are observed as in the undoped case. However it should be observed that the short-circuit current is of opposite sign as that of the undoped case. We can consider that this is due to the formation of a n-i-p structure. Using the same conditions and dose, As implantation was performed (also n-type dopant in diamond $\mathrm{Si}$, therefore also generating a $\mathrm{n}-\mathrm{i}-\mathrm{p}$ structure). Figure $5 \mathrm{~d}$ ) shows the IV curves after 
implantation by As. It can be seen that the short-circuit current has the same sign as that for $\mathrm{P}$ but the $\mathrm{J}_{\mathrm{sC}}$ and $V_{O C}$ are greatly improved, with $0.11 \mathrm{~mA} / \mathrm{cm}^{2}$ and $91 \mathrm{mV}$ respectively. The $\mathrm{J}_{\mathrm{Sc}}$ obtained is very promising and much higher than a previous attempt using undoped $\mathrm{SCF}^{8}$. The resulting efficiency is still low, about $2.5 \times 10^{-3} \%$, but more than two orders of magnitude higher than the only previous report of $10^{-5} \%^{8}$. To further understand why As implantation gave greatly improved results compared to $\mathrm{P}$ implantation, it can be reminded that $\mathrm{As}$ in diamond $\mathrm{Si}$ is well known to provide better incorporation in the lattice than P. The fill factor in all cases is low, about $25 \%$. In order to check if this low value is due to series resistances, fingers of $\mathrm{Ti}(50 \mathrm{~nm}) / \mathrm{Pd}(50 \mathrm{~nm}) / \mathrm{Ag}(1 \mu \mathrm{m})$ were deposited on SCF implanted by As and no significant improvement in the fill factor or $J_{S c}$ and $V_{O C}$ were observed. Therefore the low fill factor is probably mainly due to the poor rectifying properties of the devices. The short-circuit current decreased slightly compared to the previous case due to the reduction of active area by the fingers. 
Figure 5: Current density vs. voltage characteristics in the dark and under 1 sun for a) SCF as fabricated; b), c), d) SCF doped at the surface with B, P and As respectively.
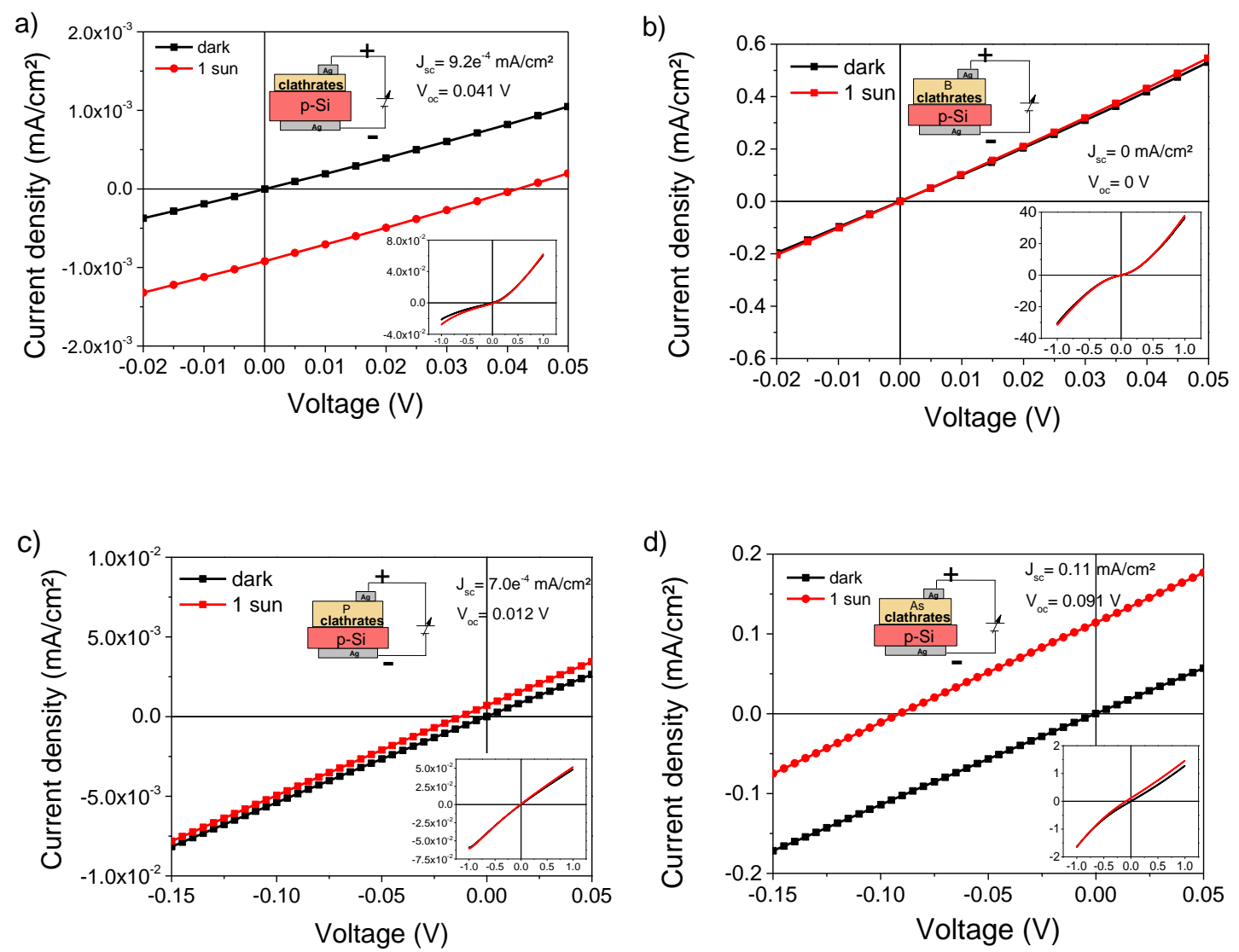

In the present work we do not demonstrate directly that the electron-hole pairs are generated in the SCF and not in the $\mathrm{p}$-Si base. The short-circuit currents were too small to measure external quantum efficiency (EQE). Further work will be to improve the $\mathrm{J}_{\mathrm{Sc}}$ and focus on the carrier generation.

\section{Conclusions}

To conclude, this work presents substantial improvement in the field of SCF. The number of laboratories capable of producing them is very limited, which was probably hindered by the fact that a dedicated glove box was necessary. With the protocol described here, we show that no glove box is needed and that most laboratories have the necessary tools to produce their own SCF. Progress was also obtained in 
the morphology of the films, thanks to pressure annealing. This allowed to obtain the first AFM images on SCF. Finally, early solar cells were produced and showed that implantation has a great impact on the PV properties and thus the SCF semiconducting behaviour. Further work will be to systematically investigate the control of doping in SCF which is the bottleneck for the improvement of PV properties with this material. To do so, SCF should be produced from Si films on insulating substrates rather than on p-Si crystalline substrates in order to allow advanced electrical characterisations.

\section{Supporting Information}

SEM images of as-grown SCF; Raman spectra of as-grown SCF; XRD spectra before and after pressure annealing; optical properties of SCF; PL spectra of as-grown SCF; Raman spectra before and after implantation and RTA.

\section{Acknowledgments}

We thank Y. Mohamed Salah, G. Schmerber and J. Bartringer for technical assistance, C. Leuvrey and J. Faerber for SEM observations, and Y. Le Gall for ion implantation. A. A. acknowledges partial support from the European Union (ERASMUS+ "MEDSOL"). This project has received financial support from the CNRS through the MITI interdisciplinary programs. 


\section{References}

(1) Kasper, J. S.; Hagenmuller, P.; Pouchard, M.; Cros, C. Clathrate Structures of Silicon. Science $1965,150,1713-1714$.

(2) Narita, T.; Ueno, H.; Baba, T.; Kume, T.; Ban, T.; lida, T.; Habuchi, H.; Natsuhara, H.; Nonomura, S. Preparation of NaSi Thin Films for the Guest Free Si Clathrate Thin Films by Heat Resistance Apparatus Using NaSi Target Materials. Phys. Status Solidi C 2010, 7, 1200-1202.

(3) Ohashi, F.; Iwai, Y.; Noguchi, A.; Sugiyama, T.; Hattori, M.; Ogura, T.; Himeno, R.; Kume, T.; Ban, T.; Nonomura, S. Thin-film Formation of Si Clathrates on Si Wafers. J. Phys. Chem. Solids 2014, 75, 518-522.

(4) Krishna, L.; Baranowski, L. L.; Martinez, A. D.; Koh, C. A.; Taylor, P. C.; Tamboli, A. C.; Toberer, E. S. Efficient Route to Phase Selective Synthesis of Type II Silicon Clathrates with Low Sodium Occupancy. CrystEngComm 2014, 16, 3940-3949.

(5) Amsler, M.; Botti, S.; Marques, M. A. L.; Lenosky, T. J.; Goedecker, S. Low-density Silicon Allotropes for Photovoltaic Applications. Phys. Rev. B 2015, 92, 014101.

(6) Krishna, L.; Koh, C. A. Inorganic and Methane Clathrates: Versatility of Guest-host Compounds for Energy Harvesting. MRS Energ. Sust. 2015, 2, E8.

(7) Gryko, J.; McMillan, P. F.; Marzke, R. F.; Ramachandran, G. K.; Patton, D.; Deb, S. K.; Sankey, O. F. Low-density Framework Form of Crystalline Silicon with a Wide Optical Band Gap. Phys. Rev. B 2000, 62, R7707-R7710.

(8) Kume, T.; Ohashi, F.; Nonomura, S. Group IV Clathrates for Photovoltaic Applications. Jpn. J. Appl. Phys. 2017, 56 (5).

(9) Chan, K. S.; Miller, M. A.; Liang, W.; Ellis-Terrell, C.; Chan, C. K. First Principles and Experimental Studies of Empty $\mathrm{Si}_{46}$ as Anode Materials for Li-ion Batteries. J. Mater. Res. 2016, 31, 3657.

(10) Chan, K. S.; Miller, M. A.; Ellis-Terrell, C.; Chan, C. K. Synthesis and Characterization of Empty Silicon Clathrates for Anode Applications in Li-ion Batteries. MRS Adv. 2016, 1, 3043-3048.

(11) Li, X. M.; Steirer, K. X.; Krishna, L.; Xiao, C. X.; Fink, K.; Santhanagopalan, S. Electrochemical Properties and Challenges of Type II Silicon Clathrate Anode in Sodium Ion Batteries. J. Electrochem. Soc. 2019, 166, A3051-A3058.

(12) Warrier, P.; Koh, C. A. Silicon Clathrates for Lithium Ion Batteries: A Perspective. Appl. Phys. Rev. 2016, 3, 040805.

(13) Chae, K.; Kang, S. H.; Choi, S. M.; Kim, D. Y.; Son, Y. W. Enhanced Thermoelectric Properties in a New Silicon Crystal $\mathrm{Si}_{24}$ with Intrinsic Nanoscale Porous Structure. Nano Lett. 2018, 18, 4748-4754.

(14) Li, J. C.; Wang, C. L.; Wang, M. X.; Peng, H.; Zhang, R. Z.; Zhao, M. L.; Liu, J.; Zhang, J. L.; Mei, L. M. A Study of the Vibrational and Thermoelectric Properties of Silicon Type I and II Clathrates. J. Appl. Phys. 2009, 105, 043503.

(15) Botti, S.; Flores-Livas, J. A.; Amsler, M.; Goedecker, S.; Marques, M. A. L. Low-energy Silicon Allotropes with Strong Absorption in the Visible for Photovoltaic Applications. Phys. Rev. B 2012, 86, 121204(R).

(16) Martinez, A. D.; Krishna, L.; Baranowski, L. L.; Lusk, M. T.; Toberer, E. S.; Tamboli, A. C. Synthesis of Group IV Clathrates for Photovoltaics. IEEE J. Photovolt. 2013, 3, 1305-1310.

(17) Wu, J. F.; Gao, H.; Xia, K.; Xing, D. Y.; Sun, J. Silicon Clathrates for Photovoltaics Predicted by a Two-step Crystal Structure Search. Appl. Phys. Lett. 2017, 111, 173904.

(18) Krishna, L.; Martinez, A. D.; Baranowski, L. L.; Brawand, N. P.; Koh, C. A.; Stevanovic, V.; Lusk, M. T.; Toberer, E. S.; Tamboli, A. C. Group IV Clathrates: Synthesis, Optoelectronic Properties, and 
Photovoltaic Applications. In Physics, Simulation, and Photonic Engineering of Photovoltaic Devices III, Freundlich, A.; Guillemoles, J. F., Eds.; Proc. SPIE 2014, 8981, 898108.

(19) Kume, T.; Ohashi, F.; Sakai, K.; Fukuyama, A.; Imai, M.; Udono, H.; Ban, T.; Habuchi, H.; Suzuki, H.; Ikari, T.; Sasaki, S.; Nonomura, S. Thin Film of Guest-free Type-II Silicon Clathrate on Si(111) Wafer. Thin Solid Films 2016, 609, 30-34.

(20) Oh, Y. J.; Lee, I.-H.; Kim, S.; Lee, J.; Chang, K. J. Dipole-allowed Direct Band Gap Silicon Superlattices. Sci. Rep. 2015, 5, 18086.

(21) Cloutier, S. G.; Kossyrev, P. A.; Xu, J. Optical Gain and Stimulated Emission in Periodic Nanopatterned Crystalline Silicon. Nat. Mater. 2005, 4, 887-891.

(22) Lecler, S.; Bastide, S.; Tan, J.; Qu, M.; Slaoui, A.; Fix, T. Plasmonic Effect of Ag Nanoparticles in a SiON Antireflective Coating: Engineering Rules and Physical Barrier. J. Phys. D: Appl. Phys. 2016, 49, 415102.

(23) Bläsi, B.; Jüchter, S.; Meisenheimer, S.-K.; Höhn, O.; Hauser, H.; Wellens, C.; Fix, T.; Schwarz, U. T. Study of Plasmonic Nanoparticle Arrays for Photon Management in Solar Cells. In Photonics for Solar Energy Systems V; Proc. SPIE 2014, 91400W.

(24) Guyot, Y.; Champagnon, B.; Reny, E.; Cros, C.; Pouchard, M.; Melinon, P.; Perez, A.; Gregora, I. Raman Scattering of Silicon Clathrates. Phys. Rev. B 1998, 57, R9475-R9477.

(25) Fang, S. L.; Grigorian, L.; Eklund, P. C.; Dresselhaus, G.; Dresselhaus, M. S.; Kawaji, H.; Yamanaka, S. Raman Scattering from Vibrational Modes in $\mathrm{Si}_{46}$ Clathrates. Phys. Rev. B 1998, 57, 76867693.

(26) Ammar, A.; Cros, C.; Pouchard, M.; Jaussaud, N.; Bassat, J. M.; Villeneuve, G.; Duttine, M.; Menetrier, M.; Reny, E. On the Clathrate Form of Elemental Silicon, Si $i_{136}$ : Preparation and Characterisation of $\mathrm{Na}_{x} \mathrm{Si}_{136}(\mathrm{x}->0)$. Solid State Sci. 2004, 6, 393-400. 
TOC graphic

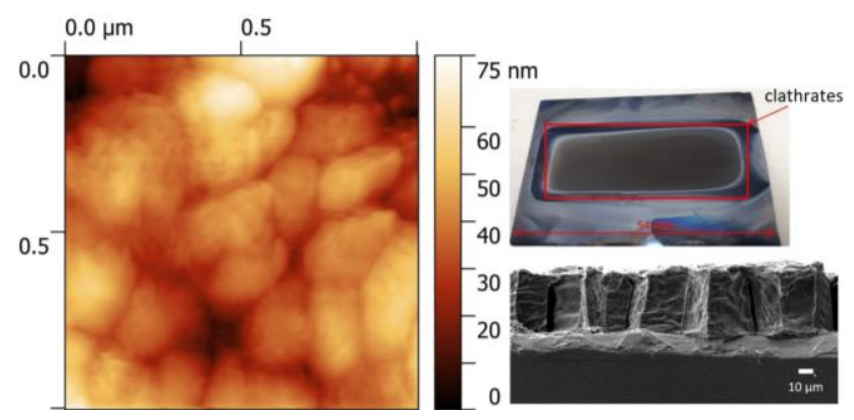

